\title{
Right sleeve pneumonectomy via uniportal video-assisted thoracoscopic approach
}

\author{
Chenlu Yang, Firas Abu Akar, Jian Chen, Lei Jiang \\ Department of Thoracic Surgery, Tongji University Affiliated Shanghai Pulmonary Hospital, Shanghai 200000, China \\ Correspondence to: Lei Jiang. Department of Thoracic Surgery, Tongji University Affiliated Shanghai Pulmonary Hospital, Zhengmin RD, 507, \\ Shanghai 200000, China. Email: jiangleiem@aliyun.com.
}

Submitted Jan 17, 2018. Accepted for publication Apr 23, 2018.

doi: $10.21037 /$ jtd.2018.05.58

View this article at: http://dx.doi.org/10.21037/jtd.2018.05.58

\section{Introduction}

With the careful preoperative patient selection, lung cancer involving the carina can be surgically treated with satisfactory immediate and long-term results (1). The rapid development of minimally invasive thoracic surgery and surgeons' acquisition of experience and new skills in this type of surgery has led to increased confidence among surgeons in their ability to perform the most challenging procedures through these techniques. In recent years, some reports have been published describing the newly acquired techniques for performing most complex operations in this field (2-4). Our department is considered to be an advanced and very high-volume center for minimally invasive thoracic surgery, dozens of uniportal VATS operations are performed daily in a routine manner in our department. After we have overstepped our learning curve in performing the standard anatomical lung resections through this technique, we found ourselves able to conduct more complex procedures such as the one we describe here through this article.

\section{Patient and workup}

A 56-year-old, male, heavy smoker patient presented to our clinic with complaints of worsening intermitted cough and hemoptysis for the last year. With the thorough history and examination, the patient denied any loss of weight, fever, hoarseness of voice or any other complaint. Physical examination was unremarkable and blood tests showed no abnormalities. CT scan was described in Figure 1A. PETCT revealed (4 SUV) pathological uptake in the lesion with no FDG uptake in the mediastinum or in another place. We also did the brain and bone scan that showed negative.
Cardiac and pulmonary functions were within normal values. Flexible bronchoscopy was described in Figure $1 B$. The bronchoscope was advanced beyond the tumor in order to explore the rest of the right bronchial tree and Figure $1 C$ shows the view of bronchus intermedius. EBUS revealed no lymph nodes involvement. A decision to perform a carinal sleeve pneumonectomy was made.

\section{Pre-operative preparation}

The operation was scheduled to be performed with intercostal uniportal VATS technique. The patient was intubated with left double lumen endotracheal tube (39 Fr), CVP line, arterial line, and urinary catheters were inserted before the beginning of the surgery.

\section{Equipment and performance card}

Full HD thoracoscopic camera $\left(\operatorname{Karl~Storz~}^{\circledR}\right)$, vascular tourniquet and wound protector (Changzhou Company Ltd.), special instruments designed for VATS surgery (Shanghai Medical Instruments Group Ltd.), $\mathrm{TA}^{\mathrm{TM}}{ }^{\mathrm{T}}$ saplers (Covidien-Medtronic), and PROLENE® sutures.

\section{Procedure}

Under general anesthesia, left double-lumen endotracheal intubation, insertion of venous access lines, arterial line and urinary catheter. The patient positioned on left decubitus position. Four $\mathrm{cm}$ incision was performed in the midaxillary line at the level of 4th intercostal space. After adhesiolysis using cautery and in a sequential manner, the 

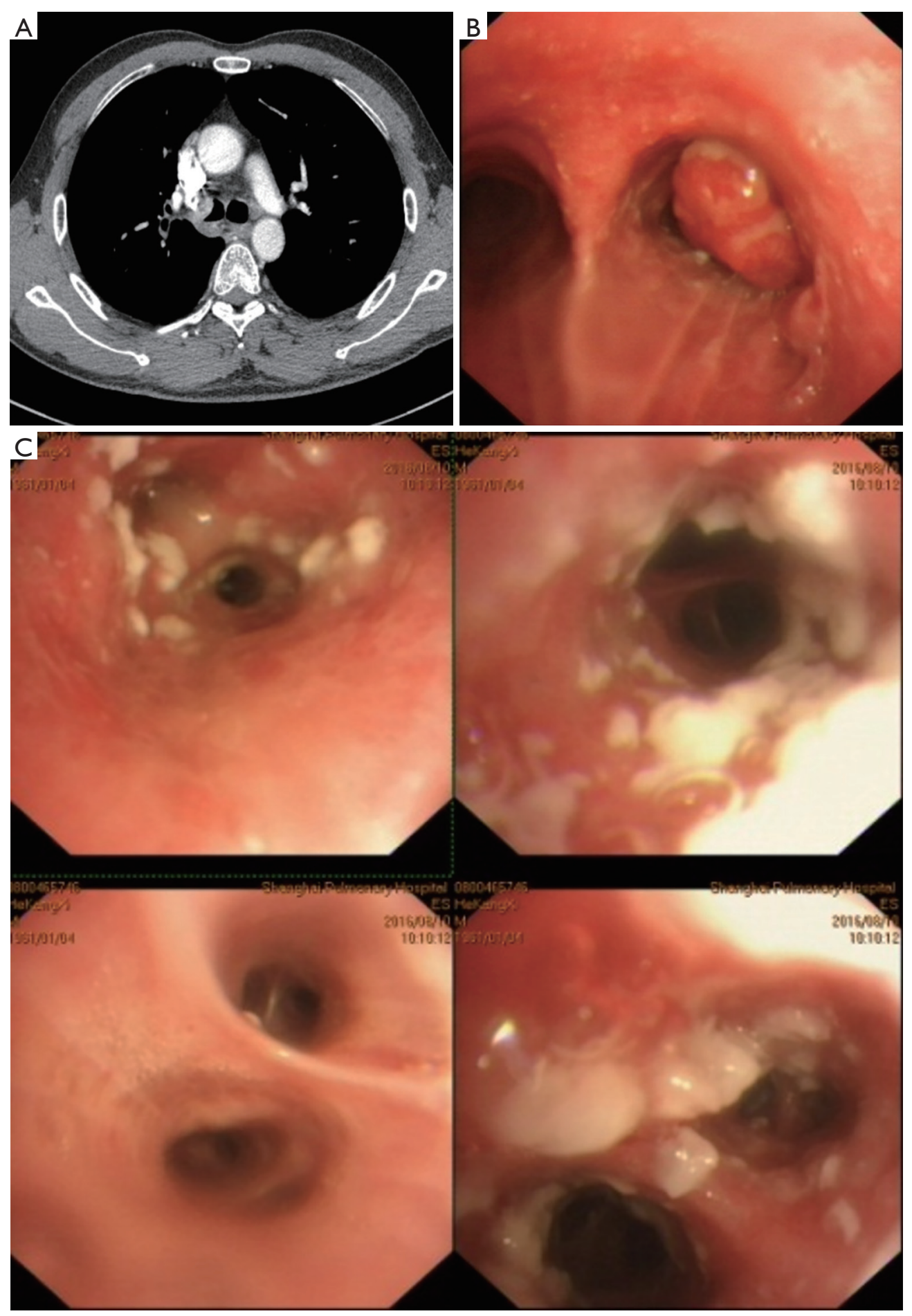

Figure 1 Preoperation test. (A) CT scan revealed a $2 \mathrm{~cm}$ endobronchial lesion invading the right main bronchus propagating proximally into the level of carina with no obvious mediastinal lymphadenopathy; (B) flexible bronchoscopy revealed a smooth rounded endobronchial lesion of the right main bronchus and extending very close to the bifurcation of the carina; (C) multiple necrotic white lesions were noticed on the wall of bronchus intermedius and the biopsy revealed a diagnosis of squamous cell carcinoma from the main lesion and atypical hyperplasia from the lesions in the bronchus intermedius. 


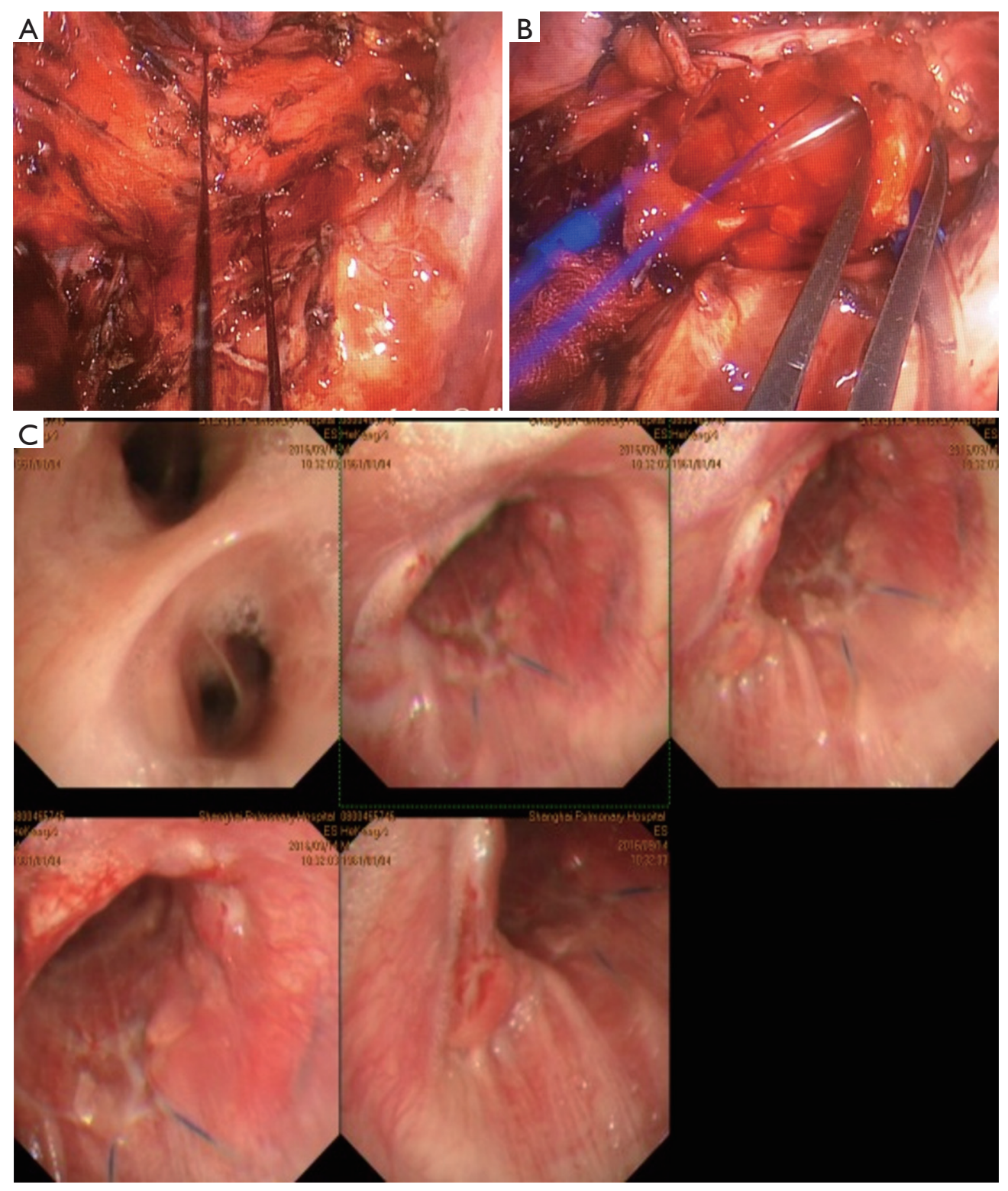

Figure 2 Operation and follow up. (A) Exposed trachea and main bronchial; (B) anastomosis of the back wall and suction for high-frequency ventilation; (C) follow up 6-month after surgery.

right inferior and superior pulmonary vein was dissected, encircled and divided using $30 \mathrm{~mm}$ white reload Endo GIA $^{\mathrm{TM}}$ stapler. The right main pulmonary artery thereafter dissected, encircled, and divided using $45 \mathrm{~mm}$ golden Endo GIA ${ }^{\mathrm{TM}}$ curved tip reload. After that, the azygos vein was divided using $30 \mathrm{~mm}$ white reload Endo GIA ${ }^{\mathrm{TM}}$ and mediastinal lymphadenectomy was performed in upper paratracheal (R2), lower paratracheal (R4) (including Azygos Nodes) and subcarinal (R7) using energy device
(LigaSure $\left.^{\mathrm{TM}}\right)$. The distal trachea and the left main bronchus were fully exposed, mobilized, and encircled with silk slings (Figure 2A), tourniquets were used to secure these slings in order to get control and apply traction during the process of anastomosis. In this stage a 15-blade scalpel attached to a curved holder used to transect the trachea above the carina and close to the origin of the left main bronchus then the right lung was removed out of the pleural cavity inside a retrieval bag. While maintaining the 

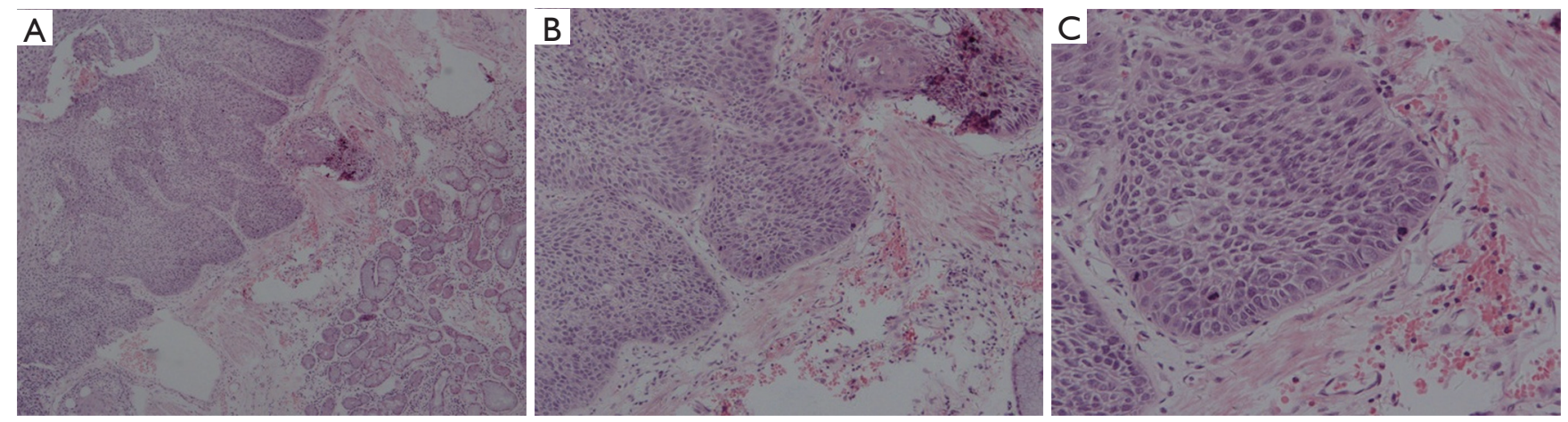

Figure 3 Histologic slide of tumor: squamous carcinoma in situ of the bronchus intermedius. Hematoxylin and eosin stain: (A) 40x times magnification; (B) 100x times magnification; (C) 200x times magnification

endotracheal tube within the left bronchus, the surgical margins were circumferentially extended. Here we began to create the anastomosis between the distal trachea and left main bronchus and using running non-absorbable two needles (PROLENE $\left.{ }^{\circledR} 3 / 0\right)$ continuous suture. We started to generate the anastomosis from the posterior wall in an anti-clockwise direction. It is important to note the vitality of the suction device during the anastomosis process, as it has great importance in directing the two ends of anastomosis and adjusting the angle to facilitate the sewing. After applying several sutures at the posterior part of the anastomosis, the endotracheal tube was withdrawn and replaced with a narrow "suction" tube for high-frequency ventilation (Figure $2 B$ ), and then the rest of the anastomosis was completed in the opposite direction (clockwise). By the end of the anastomosis, the knot was placed outside the bronchial lumen. The competency of the anastomosis was checked, and hemostasis was done. A single (28 French) chest drain was introduced to the pleural cavity through the same incision which was closed in layers thereafter. Frozen section confirmed that all the surgical margins were free of tumor cells, total surgical time was (120 minutes) and estimated blood loss was (200 cc).

\section{Post-operative management}

Post-operative course was uneventful. Postoperative radiographic X-ray showed a fully expanded left lung with no abnormalities. A chest drain was removed in POD (5), and the patient was discharged in POD (6). Follow-up bronchoscopy 6 months after the surgery revealed good healing of the anastomosis with no evidence for stenosis or gross recurrence of the tumor (Figure 2C). Follow up
CT scan 6 months after the operation showed no evidence for recurrence or complication. The final diagnosis was $2 \mathrm{~cm} \times 2 \mathrm{~cm}$ squamous cell carcinoma tumor with of lung with endobronchial mucosal extension to bronchus intermedius (T4NOM0) (Figure 3).

\section{Discussion}

Sleeve pneumonectomy is a procedure in which the involved lung with its main stem bronchus and part of the carina and/or distal trachea are removed. The remaining lung is re-implanted to the distal trachea. Although technically challenging and demanding, sleeve pneumonectomy considered to be the surgery of choice for resectable tumors invading the tracheobronchial angle.

For decades, this type of operations was performed through the conventional open thoracotomy approach. But the revolution in minimal invasive thoracoscopic techniques, which has recently emerged, has imposed itself strongly in this field due to its advantages in reducing the surgical trauma and postoperative pain $(5,6)$. The publication of the report on the first uniportal VATS lobectomy performed by Diego Gonzalez-Rivas and his group published in 2011 has opened the way for more complex operations to be conducted by the same technique (7). This is what happened. In 2013 Gonzalez and his colleagues reported the first uniportal VATS sleeve lobectomy (8). It is clear that these operations are not technically easy and require experienced surgeons to be safely and correctly conducted. The procedure may be unsafe if performed by a surgeon who did not exceed the required learning curve.

The authors believe that in expert hands uniportal thoracoscopic sleeve lung resections are safe and feasible 


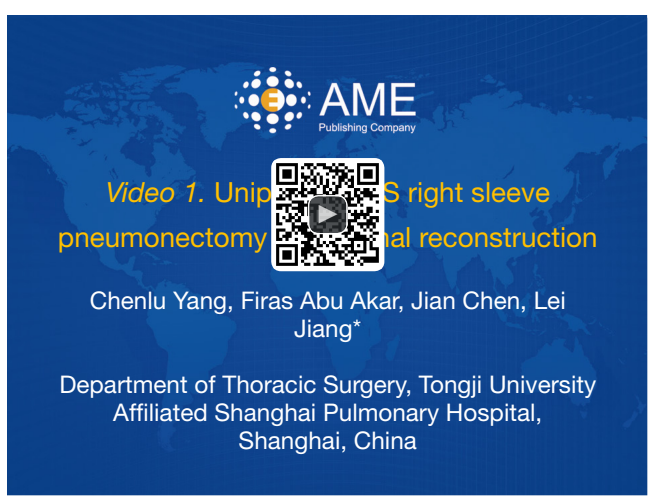

Figure 4 Uniportal VATS right sleeve pneumonectomy and carinal reconstruction (9).

Available online: http://www.asvide.com/article/view/25000

and Uniportal VATS sleeve lobectomy or pneumonectomy is a considerable choice for those intrabronchial lung cancers.

\section{Tips, tricks and pitfalls}

(I) The location of the incision is crucial in sleeve resections, the anterior axillary line of the 4th intercostal space is the most suitable site to create the incision since it provides ideal angles for visualization and accomplishment of the anastomosis.

(II) It is preferred to divide the veins before the artery, this may provide more suitable angles for stapling the main artery.

(III) The dissection of the tissue around the distal trachea and the left main bronchus should be extensive enough to expose and as much as possible the area. But at the same time, surgeon must be careful because excessive dissection may harm the anastomosis as it may disconnect blood supply from that area

(IV) Before circumferential resection, we first performed the wedge resection of the right main bronchus from the right lung to take the specimen out and reconstructed the carina, so as to accomplish enough time and space to a satisfactory anastomosis. In the early stage of anastomosis, the tracheal cannula need to be retreated and the sputum suction tube is used for high frequency ventilation. The anastomosis started in the posterior wall and followed by that in anterior wall during which the tracheal cannula can be introduced again (shown in the Figure 4).

\section{Acknowledgements}

None.

\section{Footnote}

Conflicts of Interest: The authors have no conflicts of interest to declare.

Informed Consent: Written informed consent was obtained from the patient for publication of this case report and any accompanying images.

\section{References}

1. Porhanov VA, Poliakov IS, Selvaschuk AP, et al. Indications and results of sleeve carinal resection. Eur J Cardiothorac Surg 2002;22:685-94.

2. Gonzalez-Rivas D, Delgado M, Fieira E, et al. Double sleeve uniportal video-assisted thoracoscopic lobectomy for non-small cell lung cancer. Ann Cardiothorac Surg 2014;3:E2

3. Abu Akar F, Yang C, Lin L, et al. Intra-pericardial double sleeve uniportal video-assisted thoracoscopic surgery left upper lobectomy. J Vis Surg 2017;3:51.

4. Lyscov A, Obukhova T, Ryabova V, et al. Doublesleeve and carinal resections using the uniportal VATS technique: a single centre experience. J Thorac Dis 2016;8:S235-41.

5. Yan TD, Black D, Bannon PG, et al. Systematic review and meta-analysis of randomized and nonrandomized trials on safety and efficacy of video-assisted thoracic surgery lobectomy for early-stage non-small-cell lung cancer. J Clin Oncol 2009;27:2553-62.

6. Onaitis MW, Petersen RP, Balderson SS, et al. Thoracoscopic lobectomy is a safe and versatile procedure: experience with 500 consecutivepatients. Ann Surg 2006;244:420-5.

7. Gonzalez-Rivas D, Marin JC, Granados JP, et al. Uniportal video-assisted thoracoscopic right upper sleeve lobectomy and tracheoplasty in a 10-year-old patient. J Thorac Dis 2016;8:E966-9.

8. Gonzalez-Rivas D, Fernandez R, Fieira E, et al. Uniportal video-assisted thoracoscopic bronchial sleeve lobectomy: first report. J Thorac Cardiovasc Surg 2013;145:1676-7. 
9. Yang C, Abu Akar F, Chen J, et al. Uniportal VATS right sleeve pneumonectomy and carinal reconstruction.

Cite this article as: Yang C, Abu Akar F, Chen J, Jinag L. Right sleeve pneumonectomy via uniportal video-assisted thoracoscopic approach. J Thorac Dis 2018;10(5):E391-E396. doi: $10.21037 /$ jtd.2018.05.58
Asvide 2018;5:528. Available online: http://www.asvide. com/article/view/25000 